\title{
The Development of a Measure for End-User Computing Support
}

Article in Decision Sciences · June 2007

DOI: 10.1111/j.1540-5915.1994.tb00817.x

CITATIONS

35

2 authors, including:

Rajesh Mirani

University of Baltimore

28 PUBLICATIONS 550 CITATIONS

SEE PROFILE
READS

35

Some of the authors of this publication are also working on these related projects:

Project (To be Decided) View project 


\title{
The Development of a Measure for End-User Computing Support
}

\author{
Rajesh Mirani \\ Robert G. Merrick School of Business, University of Baltimore, Baltimore, MD 21201, \\ mirani ube.ubalt.edu \\ William R. King \\ Joseph M. Katz Graduate School of Business, University of Pittsburgh, Pittsburgh, PA 15260, \\ billting@vms.cis.pitr.edu
}

\begin{abstract}
Various studies have argued and concluded that the most effective method of promoting end-user computing (EUC) in an organization consists of providing extensive end-user support. This paper describes the development of an instrument to measure EUC support. A search of the EUC literature was conducted to identify items to include in the instrument. The instrument was validated by administering it in the form of a questionnaire to end-users in more than a hundred information centers across the United States. A factor analysis conducted on the data obtained from this survey yielded 12 factors of EUC support. Three factors were subsequently dropped from the instrument. The remaining factors were successfully tested for intemal consistency. The instrument was tested for, and found to possess, convergent and discriminant validity. The instrument exhibited nomological validity. The resulting instrument, consisting of 42 items and 9 factors, is presented as a reliable, valid, and useful device for assessing the level of EUC support.
\end{abstract}

Subjoct Areas: Eloctronic Data Processing, Information Management, Management Information Systems, and Questionnaire Analysis.

\section{INTRODUCTION}

End-users are managerial, professional, and operating level personnel in functional areas such as production, marketing, finance, and human resources who use information outputs from organizational information systems in their work activities. Lacking formal training in systems analysis and design, they have traditionally depended on data processing (DP) or information systems (IS) departments to design, maintain, and run the information systems that provide them with these outputs. In the past few years, however, the evolution of powerful yet inexpensive hardware and user-friendly software has enabled end-user departments to independently acquire, control, and use an increasingly large share of organizational computing power. The use of easily accessible computing tools has resulted in end-users acquiring computing literacy, and in many cases, expertise. This has enabled them to decrease their reliance on IS departments for information. A large number of end-users now develop, maintain, and use their own IS applications for decision making, with minimal or no assistance from IS specialists. This phenomenon is known as end-user computing (EUC). 
End-users practice EUC on a variety of computing platforms such as personal computers (PCs), workstations, local area networks (LANs), mainframes, and various combinations of these. In particular, PCs and workstations are extremely popular with end-users because of their ease-of-use, availability, and the independence they offer from the control mechanisms of IS departments. A recent survey conducted by Nolan, Norton, \& Co. revealed that 55 percent of all employees now use a PC or workstation [35]. Although PCs and workstations represent just two of the several hardware platforms on which EUC is practiced, their widespread use suggests that EUC is a pervasive phenomenon. Another recent national survey of public sector managers in federal, state, and county agencies ranked EUC as one of the five most important information systems issues [13]. Depending on how well it is managed, EUC is known to either enhance organizational effectiveness or generate dysfunctional consequences.

Various research studies have noted that user satisfaction with EUC is considerably enhanced by providing end-users with appropriate types and levels of support [3] [8] [9] [25] [29] [38] [39]. User satisfaction is a widely accepted, albeit not ideal, surrogate for overall IS effectiveness. Therefore, the provision of end-user support appears to be critical to overall IS and organizational effectiveness. Given this importance of enduser support, it is imperative for IS researchers to study the causes of variations among the support needs of end-users so that these needs can be better understood, predicted, and fulfilled. For instance, it has been theorized that diversity among end-users calls for "strongly differentiated education, training, and support for the quite different classes of users" [40, p. 778]. Thus, differences in end-user characteristics, such as training, experience, and nature of EUC activities, may translate into dissimilar support needs. Similarly, differences in IS and organizational characteristics are also likely to result in differences in support needed.

In order to study the impact of various individual, IS, and organizational characteristics on support needed by end-users, a validated measuring instrument for EUC support is absolutely essential. Such a measuring instrument should capture the dimensions of EUC support so that the impact of these characteristics on the various dimensions can be closely studied. Such an instrument may also be used to study the impact of EUC support on various measures of IS and organizational effectiveness. Despite the obvious need for such an instrument, however, there has never been a formal effort in this direction. The potential impacts mentioned above have remained largely unexplored because of the lack of a measuring instrument that accurately captures the construct of EUC support. This paper describes the development of an instrument intended to capture the salient dimensions, or types, of support needed by end-users.

\section{RESEARCH METHODOLOGY}

There are three steps in the construction of an instrument to measure a construct: (1) the constitution of the pool of items, (2) the analysis of the internal structure of the pool and consequent selection of items to form a scoring key, and (3) conducting correlation analyses to examine convergent and discriminant validity [28].

\section{Constitution of the Pool of Items}

The process of instrument development must start with the construction of a universe of pooled items, from which the measure of the construct will ultimately be derived. 
There is agreement in the EUC literature that support consists of a mix of relevant services provided by the IS/DP function to aid end-users in their computing activities. There are, however, varying interpretations of what these relevant services are. Short lists of such services typically include end-user training, problem solving, maintaining hot-lines, and providing end-users with technical or administrative assistance [14]. Longer lists also mention the provision of database extracts, publishing newsletters and conducting seminars, coondinating applications development across end-user departments, establishing communication channels between end-users, and conducting ongoing research and development programs for end-users. Other support activities include performing hardware and software evaluation, ensuring differential education for various types of end-users, assisting in data transfer or data migration, providing end-users with a distributed support staff, maintaining hardware and software, encouraging the formation of user-groups, and providing end-users with backup and/or recovery assistance.

For developing this instrument, the EUC literature was thoroughly searched to identify all activities mentioned as potential support services. An exhaustive list of items of EUC support was thus constructed. It is essential to construct this exhaustive universe of pooled items by using all alternative theories of the construct (EUC support) or bases of categorization available. If only one theory or basis is used as the criterion for pool construction, there is a danger of the pool being invalidated at a later point in time as a result of the theory being proven wrong [28].

The list constructed was carefully scrutinized and modified to eliminate redundancies and to ensure that the items were mutually exclusive. It must be emphasized here that the sole consideration in the selection of items was the identification of various types of support needed by users. This is because the purpose of the intended instrument was to uncover the underlying dimensions of the content of EUC support so that these could be differentiated and analyzed separately.

Following the construction of this list, five academic experts in the field were asked to individually examine the list and to suggest changes. They were informed that they were free to add, delete, or change items. A few changes were proposed by them, and the list was revised.

This revised list was individually pretested with five IS executives in five randomly selected business organizations in the Pittsburgh area. After suggesting a few minor changes during these sessions, all the executives agreed that the list was exhaustive and consisted of mutually exclusive items.

Changes that were suggested by more than one IS executive were incorporated into the list. This modified list consists of 54 items, and is depicted in Table 1. Every item in this list was mentioned as a support activity in at least two references from the EUC literature. However, for the sake of brevity, this table indicates only one reference as a primary source for each item, and not all the sources referred to have been reported here.

It may be noted that the items in Table 1 have been arranged such that items follow one another in intuitive groups. Thus, items 1 to 18 identify various subjects on which end-users may be provided training and education. These include the uses and capabilities of end-user software and languages, systems analysis, cost justification, the selection of tools, activities related to application development, backups/security, operating systems, and others. Item 19 relates to hardware-related services such as establishing micromainframe links, and purchasing and installing hardware. Items 20 to 28 consist of 
Table 1: Measurement of EUC support: Pool of items.

\begin{tabular}{ll}
\hline Item Included & Reference \\
\hline 1. Training on uses and capabilities of end-user languages & {$[40]$} \\
2. Training on uses and capabilities of end-user software & {$[38]$} \\
3. Training on statistical analysis & {$[7]$} \\
4. Training on systems analysis & {$[7]$} \\
5. Training on application selection and cost justification & {$[16]$} \\
6. Training on tool/product selection for application & {$[38]$} \\
7. Training on application development methodologies & {$[1]$} \\
8. Training on application testing/debugging & {$[34]$} \\
9. Training on application documentation & {$[5]$} \\
10. Training on application maintenance & {$[1]$} \\
11. Training on backups/security & {$[36]$} \\
12. Training on data integrity/validation & {$[33]$} \\
13. Training on logical data modeling & {$[33]$} \\
14. Training on file management and database technology & {$[7]$} \\
15. Training on data communications & {$[7]$} \\
16. Training on operating systems & {$[34]$} \\
17. Training on software conversions & {$[7]$} \\
18. Training on technology updates & {$[7]$} \\
19. Hardware-related services (e.g., micro-mainframe links, & {$[10]$} \\
purchase and installation, etc.) & \\
20. Providing software backup/recovery service & {$[27]$} \\
21. Providing help facilities for software & {$[31]$} \\
22. Supporting fourth generation languages & {$[14]$} \\
23. Supporting a variety of other languages & {$[14]$} \\
24. Supporting a variety of applications development software & {$[1]$} \\
25. Conducting software demonstrations & {$[17]$} \\
26. Listing software resources: software libraries & {$[1]$} \\
27. Developing macros and job control statements & {$[14]$} \\
28. Software purchase and evaluation & {$[43]$} \\
29. Maintaining data integrity and currency & {$[17]$} \\
\hline
\end{tabular}

software-related services such as listing software resources, providing help facilities for software, and developing macros and job control statements. Items 29 to 34 consist of data-related services such as listing corporate-wide data resources, facilitating data sharing, and providing data extraction facilities. Services related to user-developed applications are identified in items 35 to 37 . These include auditing user-developed applications, conducting maintenance reviews, and coordinating applications development across users. Hardware standards and guidelines are the focus of items 38 to 41 . Examples of hardware standards are the standardization of the hardware to be used, listing approved hardware vendors, and outlining formal procedures for getting hardware purchase approved. Items 42 to 48 identify various types of software standards and guidelines. Items 49 and 50 deal with data standards and guidelines. Items 51 and 52 consist of delineation of end-user and staff roles, and outlining domains for userdeveloped applications. Item 53 refers to the structure of support staff, and item 54 refers to the specialization of support staff. 
Table 1: (continued).

\begin{tabular}{ll}
\hline Item Included & Reference \\
\hline 30. Providing backuphrecovery service & {$[17]$} \\
31. Listing corporate-wide data resources & {$[27]$} \\
32. Providing corporate data extraction facilities & {$[41]$} \\
33. Facilitating data sharing among users & {$[40]$} \\
34. Maintaining subject data bases & {$[16]$} \\
35. Auditing user-developed applications & {$[30]$} \\
36. Conducting maintenance reviews of user-developed applications & {$[10]$} \\
37. Coordinating applications across users & {$[43]$} \\
38. Standardization of hardware to be used & {$[24]$} \\
39. Listing approved hardware vendors & {$[24]$} \\
40. Outlining formal procedures for getting hardware & {$[24]$} \\
purchase approved & \\
41. Establishment of communication protocols & {$[24]$} \\
42. Standardization of programming languages & {$[24]$} \\
43. Standardization of applications development software & {$[24]$} \\
44. Standardization of operating systems & {$[24]$} \\
45. Establishment of guidelines for systems analysis, design, & {$[1]$} \\
testing, documentation, and maintenance & \\
46. Establishment of guidelines for software backups & {$[1]$} \\
47. Listing approved software vendors & {$[7]$} \\
48. Outlining formal procedures for getting software purchase approved & {$[17]$} \\
49. Establishment of standards for data backup & {$[1]$} \\
50. Establishment of guidelines for use and modification & {$[1]$} \\
of corporate data & {$[33]$} \\
51. Delineation of end-user and staff roles & {$[1]$} \\
52. Outlining domains for user-developed applications & {$[4]$} \\
53. Existence of a local (departmental) support staff & {$[12]$} \\
54. Specialization of support staff &
\end{tabular}

\section{Data Collection}

This instrument was validated by administering it in the form of a questionnaire to end-users supported by information centers (ICs). ICs were chosen as the setting for this study because end-users have rated them as their most important source of support for EUC [10]. Questionnaires were mailed to the IC managers of 548 U.S. organizations. These managers were identified by scanning job titles from the mailing list of a trade journal specializing in ICs. This was done to ensure the selection of appropriate participants for the study. Three questionnaires were mailed to each IC. Two of the three questionnaires were intended for end-users and one for the IC manager. Each IC manager was requested to forward the end-user questionnaires to two end-users supported by the IC. The IC managers were requested to select two users who represented opposite sides on the spectrum of computing sophistication or ability. This was done to ensure that users with a wide variety of computing skills participated in the study.

The questionnaire for the IC manager was designed to collect demographic information. IC managers were asked about the size of the IC staff, the number of end-users 
supported, the annual budget of the IC, the age of the IC, and whether or not users were charged for IC services.

The end-user questionnaire consisted of the support items listed in Table 1. A seven-point scale ranging from "low" to "high" was placed next to each item. On each scale, users indicated the extent of their need for the type of support described by the corresponding item, regardless of whether the IC provided it. These responses were subsequently subjected to various statistical analyses to assess instrument validity, as described in the next section.

On a second, identical scale placed next to each item, users indicated the extent to which the type of support described by the item was provided to them by the IC, regardless of their need for it. The data from these responses were used to assess nomological validity for the instrument, as described later.

The end-user questionnaire also included the 12-item Ives, Olson, and Baroudi measure of user information satisfaction [19], modified slightly to adapt to the EUC context. Seven-point scales were provided for each item. The questionnaire also consisted of brief descriptions of the first four of Rockart and Flannery's six user categories in order for the respondents to indicate the category that best described them [40]. The user responses to all these questions were used to test the nomological validity of the EUC support measure, as described later.

After reminders, 114 IC managers and 169 end-users from these 114 ICs mailed back completed questionnaires. Thirteen addressees returned the packets mailed to them, either because their ICs had been disbanded, or because it was against company policy to respond to surveys. This translates to a response rate of 21.3 percent. This is a typical response rate for such surveys, and is good considering that an IC was deemed to have responded only when the IC manager as well as at least one end-user had completed and returned their respective questionnaires.

One possible bias of the methodology used is that the ICs to whom the questionnaires were mailed were not representative of the overall IC population. Another possible bias is that responding ICs were not representative of the larger group of ICs contacted. However, the diverse demographics of the responding ICs suggest that they comprise a good representative sample of the overall IC population.

For instance, the number of users supported by the responding ICs ranged from 10 to 40,000 . Staff sizes varied between 1 and 45 . IC annual budgets ranged from $\$ 2,500$ to $\$ 40$ million. Only 75 ICs reported their annual budgets, probably because some ICs do not have separate budgets from their IS departments. IC age varied between 5 months and 10 years. Table 2 summarizes these demographics using percentiles. For example, the smallest staff size was one. Twenty-five percent of all ICs had staff sizes not exceeding three, 50 percent did not exceed five, and 75 percent did not exceed nine. The largest staff size was 45 .

The distribution of the responding end-users is presented in Table 3. From here, the respondents are seen to be fairly uniformly distributed among Rockart and Flannery's four end-user categories.

\section{Construct Validity}

The construct validity of a measuring instrument refers to how well the instrument measures the concept or construct that it has been designed to measure. Construct 
Thble 2: IC characteristics.

\begin{tabular}{ccccc}
\hline & \multicolumn{4}{c}{ IC Characteristic } \\
\cline { 2 - 5 } Percentile & $\begin{array}{r}\text { Number } \\
\text { of Users }\end{array}$ & $\begin{array}{l}\text { Number } \\
\text { of Staff }\end{array}$ & $\begin{array}{c}\text { Budget } \\
\text { (\$ million) }\end{array}$ & $\begin{array}{c}\text { Age } \\
\text { (months) }\end{array}$ \\
\hline 0 & 10 & 1 & .002 & 5 \\
25 & 250 & 3 & .200 & 30 \\
50 & 500 & 5 & .350 & 48 \\
75 & 2000 & 9 & .620 & 66 \\
100 & 40000 & 45 & 40.000 & 120 \\
\hline
\end{tabular}

Table 3: Distribution of responding end-users.

\begin{tabular}{lcc}
\hline End-User Category & Number of Users & Percentages \\
\hline Non-programming end users & 42 & 24.85 \\
Command level users & 37 & 21.89 \\
End user programmers & 37 & 21.89 \\
Functional support personnel & 47 & 27.81 \\
Other & 6 & 3.55 \\
$\quad$ Total & 169 & 100.00 \\
\hline
\end{tabular}

validity for this instrument had been partly ensured by the comprehensive method followed in the identification and refinement of items in the pool.

A factor analysis was conducted on the 54 scales that measured support needed by end-users. This was done to uncover the underlying dimensions (factors) of the measure of EUC support and thereby enhance construct validity [22]. Items in the measure that did not load significantly with any factor were eliminated from the measure.

A principal components factor analysis followed by a VARIMAX orthogonal rotation of the axes was conducted to identify the orthogonal factors in the measure used for EUC support [23]. From this analysis, 12 factors with eigenvalues greater than one emerged; the extracted factors accounted for more than 71 percent of the total variance in the data. These factors were interpreted as follows: factor 1-applications development support; factor 2-standards and guidelines; factor 3-data provision support; factor 4 -operational support; factor 5-purchasing-related support; factor 6-variety of software supported; factor 7-support staff characteristics; factor 8post-development support; factor 9-backups/security; factor 10-training on statistical analysis; factor 11-hardware-related services; and factor 12-developing macros and job control statements. Factors 10,11, and 12 consisted of only one item each. Only those items with factor loadings greater than .5 were retained for further analysis [42]; thus, of the 54 items, 9 were eliminated (items $1,2,4,7,13,21,25,28$, and 52 in Table 1). Factors 10,11, and 12 were also dropped from the measure as they consisted of only one item each, and because their contribution to the explained variance 
was extremely low. This brought the number of items eliminated from the measure to a total of 12 . Thus, 42 items and 9 factors remained in the measure.

Given the assumption that the mean score for each factor of EUC support is valid, an examination of the correlations between individual item scores and the mean scores of their respective factors is an acceptable method for construct validation. Therefore, to avoid spurious correlations, each item was correlated with the mean score of its appropriate factor minus that item. These correlations ranged from .36 to .87 , and all were significant at the .001 level. Table 4 presents the relevant data.

To assess the stability of the factor-structure for this instrument, an independent examination of the screen plot of eigenvalues was conducted. This plot suggested nine factors, which was consistent with the number of factors remaining after conducting the validation tests described above. Thus, the nine factor structure for EUC support was found to be stable.

\section{Reliability}

Because the overall measure was found to consist of several factors or dimensions, the reliability of each factor was evaluated by means of Cronbach's alpha coefficient. Cronbach's alpha is a widely accepted test for the intemal consistency of a measure. The values of the alpha coefficients for all factors ranged from .70 to .92 . Values of .70 or higher are normally considered to be acceptable [32]. Table 5 summarizes the alpha values.

\section{Convergent and Discriminant Validity}

Convergent validity of a measure for a construct is the extent to which the measure agrees (correlates) with alternative measures of the same construct. Discriminant validity of a measure is the extent to which the measure of a construct disagrees (does not correlate well) with measures of other constructs.

Convergent validity of this instrument was tested by computing inter-item correlations within each factor (Table 6). High inter-item correlations within each factor were construed as indications of convergent validity. All the correlations shown in Table 6 are significant at the .001 level. These figures provide good evidence of convergent validity. In all, only 27 out of the 92 inter-item correlations were less than .5 .

Discriminant validity was assessed as follows. For each item, its correlations with items in the same factor were compared to its correlations with items in other factors. Whenever the correlation of an item with an item from another factor was found to be greater than its correlation with an item from the same factor, this was construed as a violation of discriminant validity. Thus, if the total number of items in any factor was $x$, then the number of such comparisons conducted for any one item belonging to that factor was $(x-1)(42-x)$, where 42 represents the total number of items in all nine factors. Therefore, the total number of comparisons conducted for all items in that factor was $x$ times $(x-1)(42-x)=x(x-1)(42-x)$. Table 7 documents, for each factor, the total number of comparisons conducted, the total number of violations encountered during these comparisons, and the number of violations expressed as a percentage of the number of comparisons. It is seen from this table that for eight of the nine factors, the percentage of violations was a single digit number. For two of these factors, the percentage was zero. For factor 3 , the percentage was slightly over 11 percent. These low percentages are evidence of discriminant validity. 
Table 4: Construct validity.

\begin{tabular}{lcc}
\hline Factor & $\begin{array}{c}\text { Factor } \\
\text { Loading }\end{array}$ & $\begin{array}{c}\text { Correlation } \\
\text { with Factor }\end{array}$ \\
\hline
\end{tabular}

Factor 1: Applications Development Support

(eigenvalue=19.71, percentage of variance $=36.5 \%$ )

Training on application testing/debugging

Training on application documentation

Training on application maintenance

Training on data integrity/validation

Training on file management and database technology

Factor 2: Standards and Guidelines

(eigenvalue $=3.87$, percentage of variance $=7.2 \%$ )

Standardization of programming languages

Standardization of applications development software

Standardization of operating systems

Guidelines for systems analysis, applications design,

testing, documentation, and maintenance

Guidelines for software backups

Standards for data backup

Guidelines for use and modification of corporate data

Factor 3: Data Provision Support

(eigenvalue $=3.70$, percentage of variance $=6.9 \%$ )

Maintaining data integrity and currency

Providing data backup/recovery service

Listing corporate-wide data resources

Providing corporate data extraction facilities

Facilitating data sharing among users

Maintaining subject databases

Factor 4: Operational Support

(eigenvalue $=2.08$, percentage of variance $=3.9 \%$ )

Training on application selection and cost justification

Training on tool/product selection

Training on data communications

Training on operating systems

Training on software conversions

Technology updates

Listing software resources: software libraries

Factor 5: Purchasing-Related Support

(eigenvalue $=1.97$, percentage of variance $=3.7 \%$ )

Standardization of hardware to be used

Listing approved hardware vendors

Outlining formal procedures for getting hardware purchase approved

Establishment of communication protocols

Listing approved software vendors

Outlining formal procedures for getting software purchase approved 
Table 4: (continued).

\begin{tabular}{|c|c|c|}
\hline Factor & $\begin{array}{c}\text { Factor } \\
\text { Loading }\end{array}$ & $\begin{array}{l}\text { Correlation } \\
\text { with Factor }\end{array}$ \\
\hline \multicolumn{3}{|l|}{$\begin{array}{l}\text { Factor 6: Variety of Software Supported } \\
\text { (eigenvalue }=1.80 \text {, percentage of variance }=3.3 \% \text { ) }\end{array}$} \\
\hline Supporting 4GLs & .61 & .70 \\
\hline Supporting applications development software & .67 & .64 \\
\hline Supporting a variety of other languages & .70 & .73 \\
\hline \multicolumn{3}{|l|}{$\begin{array}{l}\text { Factor 7: Support Staff Characteristics } \\
\text { (eigenvalue=1.69, percentage of variance }=3.1 \% \text { ) }\end{array}$} \\
\hline Delineation of end-user and staff roles & .60 & .52 \\
\hline Existence of a local support staff & .78 & .59 \\
\hline Specialization of support staff & .67 & .57 \\
\hline \multicolumn{3}{|l|}{$\begin{array}{l}\text { Factor 8: Post-Development Support } \\
\text { (eigenvalue }=1.51 \text {, percentage of variance }=2.8 \% \text { ) }\end{array}$} \\
\hline Auditing user-developed applications & .65 & .87 \\
\hline $\begin{array}{l}\text { Conducting maintenance reviews of user-developed } \\
\text { applications }\end{array}$ & .59 & .86 \\
\hline Coordinating applications across users & .54 & .76 \\
\hline \multicolumn{3}{|l|}{$\begin{array}{l}\text { Factor 9: Backups/Security } \\
\text { (eigenvalue }=1.30 \text {, percentage of variance }=2.4 \% \text { ) }\end{array}$} \\
\hline Training on backups/security & .71 & .36 \\
\hline Providing software backup/recovery service & .52 & .54 \\
\hline $\begin{array}{l}\text { Factor 10: Training on Statistical Analysis } \\
\text { (eigenvalue }=1.16 \text {, percentage of variance }=2.2 \% \text { ) }\end{array}$ & .82 & - \\
\hline $\begin{array}{l}\text { Factor 11: Hardware-Related Services } \\
\text { (eigenvalue }=1.14 \text {, percentage of variance }=2.1 \% \text { ) }\end{array}$ & .79 & - \\
\hline $\begin{array}{l}\text { Factor 12: Developing Macros and Job Control Statements } \\
\text { (eigenvalue }=1.07 \text {, percentage of variance }=2.0 \% \text { ) }\end{array}$ & .66 & - \\
\hline
\end{tabular}

Note: Spurious correlations were avoided by removing each item from its factor before computing the correlation of the factor with that item.

All coefficients are significant at the .001 level.

Factors 10,11, and 12 were dropped from the measure.

\section{Nomological Validity}

The nomological validity of a measure is established by demonstrating that the construct in question, as represented by the measure, behaves according to predictions derived from theory, in relation to other constructs in the nomological network. Numerous studies in the EUC area have concluded that the provision of EUC support enhances end-user satisfaction [3] [8] [9] [38] [40]. In order to test whether our measure of EUC support also demonstrated this expected relationship, the correlations of each factor of EUC support provided with end-user satisfaction were examined. Scores for each factor (dimension) of EUC support provided were computed by averaging the scores for support provided for each item included in the factor. 
Table 5: Internal consistency of measures.

\begin{tabular}{lcc}
\hline Scale & Number of Items & Cronbach's $\alpha$ \\
\hline Factor 1 & 5 & .85 \\
Factor 2 & 7 & .91 \\
Factor 3 & 6 & .86 \\
Factor 4 & 7 & .88 \\
Factor 5 & 6 & .92 \\
Factor 6 & 3 & .83 \\
Factor 7 & 3 & .72 \\
Factor 8 & 3 & .91 \\
Factor 9 & 2 & .70 \\
Factor 10 & 1 & - \\
Factor 11 & 1 & - \\
Factor 12 & 1 & - \\
\hline
\end{tabular}

Note: Cronbach's alpha cannot be computed for single-item measures.

Factors 10,11 , and 12 were previously dropped from the measure.

End-user satisfaction is a commonly accepted surrogate for information systems effectiveness. Thus, much attention has been showered on building instruments to measure this construct [6] [19] [20] [37]. Of these, the Ives et al. instrument for measuring "user information satisfaction" is the most universally accepted and used [19]. Doll and Torkzadeh [15] developed an instrument that measures "end-user computing satisfaction" of an end-user with a specific application. Their instrument was unsuitable for this research because the end-users in this study were developing and using several applications and the intent was to measure their overall satisfaction with end-user computing, not with a single application.

Therefore, end-user satisfaction was measured using the short form Ives et al. [19] questionnaire, modified slightly to make it specific to the EUC context. The few modifications made were minor and most of them entailed replacing the word IS with IC in the items comprising the instrument. Users were asked for their perceptions on these 12 items relating to their EUC activities. A seven-point scale was used to assess user perceptions on each item. The modified items and their scales are depicted in Table 8.

The modified instrument was validated by means of a principal components analysis. This analysis revealed three factors, which were interpreted as follows: factor 1-quality of IC staff; factor 2-quality of output from EUC; and factor 3-end-user competence. These factors are very similar to the three factors identified by Igbaria and Nachman [18], who had tested a similar 13-item instrument for the same purpose. In their study, the three factors identified had been named EDP staff and services, information prod-. uct, and knowledge and involvement.

The results of the correlations analysis are summarized in Table 9. The means of the support provided scores for all nine factors were found to be positively correlated with end-user satisfaction. Correlations ranged from .17 to .39 . The strongest correlations were with factor 7 (support staff characteristics), factor 4 (operational support), and factor 1 (applications development support). 
Table 6: Convergent validity.

Factor 1: Applications Development Support

\begin{tabular}{llllll} 
& $\mathrm{I}$ & $\mathrm{I}$ & $\mathrm{I10}$ & $\mathrm{I12}$ & $\mathrm{I1}$ \\
\hline $\mathrm{I} 8$ & 1 & & & & \\
$\mathrm{I} 9$ & .60 & 1 & & & \\
$\mathrm{I} 10$ & .65 & .72 & 1 & & \\
$\mathrm{I} 12$ & .47 & .58 & .57 & 1 & \\
$\mathrm{I} 14$ & .49 & .49 & .45 & .49 & 1 \\
\hline
\end{tabular}

Factor 2: Standards and Guidelines

\begin{tabular}{llllllll} 
& 142 & $\mathrm{I} 43$ & $\mathrm{I} 44$ & $\mathrm{I} 45$ & $\mathrm{I} 46$ & $\mathrm{I49}$ & $\mathrm{I50}$ \\
\hline $\mathrm{I} 42$ & 1 & & & & & & \\
$\mathrm{I} 43$ & .90 & 1 & & & & & \\
$\mathrm{I} 44$ & .72 & .73 & 1 & & & & \\
$\mathrm{I} 45$ & .67 & .71 & .60 & 1 & & & \\
$\mathrm{I} 46$ & .49 & .53 & .67 & .60 & 1 & & \\
$\mathrm{I} 49$ & .50 & .47 & .50 & .46 & .68 & 1 & \\
150 & .61 & .63 & .52 & .60 & .53 & .67 & 1 \\
\hline
\end{tabular}

Factor 3: Data Provision Support

\begin{tabular}{lllllll} 
& $\mathrm{I} 29$ & $\mathrm{I} 30$ & $\mathrm{I} 31$ & $\mathrm{I} 32$ & $\mathrm{I33}$ & $\mathrm{I34}$ \\
\hline $\mathrm{I29}$ & 1 & & & & & \\
$\mathrm{I30}$ & .67 & 1 & & & & \\
$\mathrm{I} 31$ & .34 & .39 & 1 & & & \\
$\mathrm{I} 32$ & .38 & .38 & .75 & 1 & & \\
133 & .48 & .52 & .63 & .64 & 1 & \\
$\mathrm{I34}$ & .46 & .49 & .45 & .52 & .60 & 1 \\
\hline
\end{tabular}

Factor 4: Operational Support

\begin{tabular}{llllllll} 
& I5 & I6 & I15 & I16 & I17 & I18 & 126 \\
\hline 15 & 1 & & & & & & \\
$\mathrm{I} 6$ & .73 & 1 & & & & & \\
$\mathrm{I} 15$ & .51 & .51 & 1 & & & & \\
$\mathrm{I} 16$ & .45 & .51 & .62 & 1 & & & \\
$\mathrm{I} 17$ & .38 & .41 & .45 & .54 & 1 & & \\
118 & .43 & .48 & .53 & .59 & .59 & 1 & \\
$\mathrm{I} 26$ & .40 & .43 & .52 & .51 & .46 & .59 & 1 \\
\hline
\end{tabular}

To further test the implication that the instrument possessed nomological validity, an analysis was conducted to examine whether all types of users (from Rockart and Flannery's categories) perceived similar needs for support. Several researchers have implied that the support needs of end-users increase with their computing sophistication [2] [21] [26] [27] [33] [40]. 
Table 6: (continued).

\begin{tabular}{lcccccc}
\multicolumn{6}{l}{ Factor 5: Purchasing-Related Support } \\
& $\mathrm{I} 38$ & $\mathrm{I} 9$ & $\mathrm{I} 90$ & $\mathrm{I} 91$ & $\mathrm{I} 97$ & 148 \\
\hline $\mathrm{I} 38$ & 1 & & & & & \\
$\mathrm{I} 39$ & .70 & 1 & & & & \\
$\mathrm{I} 40$ & .62 & .76 & 1 & & & \\
$\mathrm{I} 41$ & .67 & .70 & .76 & 1 & & \\
$\mathrm{I} 17$ & .54 & .73 & .61 & .57 & 1 & \\
$\mathrm{I} 48$ & .58 & .66 & .73 & .62 & .70 & 1 \\
\hline
\end{tabular}

Factor 6: Variety of Software Supported

\begin{tabular}{llll} 
& 122 & 123 & 124 \\
\hline 122 & 1 & & \\
123 & .68 & 1 & \\
124 & .57 & .61 & 1 \\
\hline
\end{tabular}

Factor 7: Support Staff Characteristics

\begin{tabular}{llll} 
& I51 & I53 & I54 \\
\hline $\mathbf{I 5 1}$ & 1 & & \\
153 & .46 & 1 & \\
154 & .44 & .53 & 1 \\
\hline
\end{tabular}

Factor 8: Post-Development Support

\begin{tabular}{llll} 
& 135 & 136 & 137 \\
\hline 135 & 1 & & \\
136 & .87 & 1 & \\
137 & .74 & .74 & 1 \\
\hline
\end{tabular}

Factor 9: Backups/Security

\begin{tabular}{lll} 
& I11 & I20 \\
\hline I11 & 1 & \\
120 & .54 & 1 \\
\hline
\end{tabular}

End-user computing sophistication was measured by using the first four of Rockart and Flannery's categories [40]. In their six-way categorization, the first four categories represent true end-users, and the last two consist of programmers and data processing personnel. The first four categories form a spectrum of EUC sophistication in which non-programming end-users are computing novices, and functional support personnel are the most sophisticated users. The other two categories, command level users and end-user programmers, represent intermediate levels of EUC sophistication.

As mentioned earlier, end-users were provided brief descriptions of each category and asked to indicate which one category best described them. An analysis of variance 
Table 7: Discriminant validity: Comparing within-factor item correlations to acrossfactor item correlations.

\begin{tabular}{lcccc}
\hline Factor & $\begin{array}{c}\text { Number of } \\
\text { Items in Factor }\end{array}$ & $\begin{array}{c}\text { Maximum Possible } \\
\text { Violations }\end{array}$ & $\begin{array}{c}\text { Actual } \\
\text { Violations }\end{array}$ & $\begin{array}{c}\text { Actual Violations as } \\
\text { a Percentage of } \\
\text { Maximum Possible } \\
\text { Violations }\end{array}$ \\
\hline Factor 1 & 5 & 740 & 36 & 4.86 \\
Factor 2 & 7 & 1470 & 37 & 2.52 \\
Factor 3 & 6 & 1080 & 119 & 11.02 \\
Factor 4 & 7 & 1470 & 76 & 5.17 \\
Factor 5 & 6 & 1080 & 1 & .09 \\
Factor 6 & 3 & 234 & 0 & .00 \\
Factor 7 & 3 & 234 & 17 & 7.26 \\
Factor 8 & 3 & 234 & 0 & .00 \\
Factor 9 & 2 & 80 & 5 & 6.25 \\
\hline
\end{tabular}

Note: A violation occurs when the correlation of an item with another item from the same factor is less than its correlation with another item from a different factor.

Table 8: End-user satisfaction instrument.

\begin{tabular}{llll}
\hline Item & & \multicolumn{2}{c}{ Scale } \\
\hline Relationship with IC staff & Bad & $\ldots$ & Good \\
Communication with IC staff & Vague & $\ldots$ & Precise \\
Attitude of IC staff & Negative & $\ldots$ & Positive \\
Degree of training provided & Insufficient & $\ldots$ & Sufficient \\
$\begin{array}{l}\text { Speed and quality of IC response } \\
\text { to service requests }\end{array}$ & Bad & $\ldots$ & Good \\
Relevance of output & & & \\
Accuracy of output & Irrelevant & $\ldots$ & Relevant \\
Precision of output & Inaccurate & $\ldots$ & Accurate \\
Completeness of output & Imprecise & $\ldots$ & Precise \\
Speed of EUC activities & Incomplete & $\ldots$ & Complete \\
Applications understanding & Slow & $\ldots$ & Fast \\
Perceived participation in IS function & Bad & $\ldots$ & Good \\
\hline
\end{tabular}

(ANOVA) indicated that the perceived support needs of the four different types of end-users were not the same. The extent of support needed, as anticipated, increased from non-programming end-users to command level users, from command level users to end-user programmers, and from end-user programmers to functional support personnel (Table 10).

The $t$-tests demonstrated that the differences between non-programming end-users and command level users, and between command level users and functional support personnel, were statistically significant at the .05 level. The difference between end-user 
Table 9: Correlations of support provided with end-user satisfaction.

\begin{tabular}{lc}
\hline Aspect of Support Provided & Correlation with End-User Satisfaction \\
\hline Factor 1: Applications Development Support & $.35(p \leq .001)$ \\
Factor 2: Standards and Guidelines & $.23(p \leq .001)$ \\
Factor 3: Data Provision Support & $.28(p \leq .001)$ \\
Factor 4: Operational Support & $.37(p \leq .001)$ \\
Factor 5: Purchasing-Related Support & $.17(p \leq .001)$ \\
Factor 6: Variety of Software Supported & $.28(p \leq .001)$ \\
Factor 7: Support Staff Characteristics & $.39(p \leq .001)$ \\
Factor 8: Post-Development Support & $.25(p \leq .001)$ \\
Factor 9: Training on Backups/Security & $.26(p \leq .001)$ \\
\hline
\end{tabular}

Table 10: End-user computing sophistication and support needed: Analysis of variance.

\begin{tabular}{lcccc}
\hline & $\begin{array}{c}\text { Non- } \\
\text { programming } \\
\text { End Users }\end{array}$ & $\begin{array}{c}\text { Command Level } \\
\text { Users }\end{array}$ & $\begin{array}{c}\text { End User } \\
\text { Programmers }\end{array}$ & $\begin{array}{c}\text { Functional } \\
\text { Support Personnel }\end{array}$ \\
\hline $\begin{array}{l}\text { Sample size } \\
\begin{array}{l}\text { Support needed } \\
\text { (mean) }\end{array}\end{array}$ & 42 & 37 & 37 & 47 \\
\hline
\end{tabular}

Note: $F=4.93, p \leq .002$

programmers and functional support personnel was significant at the .1 level (Table 11). These results lend further credence to the assertion that the instrument developed is nomologically valid. The observed relationships between the various constructs from the above analyses are completely consistent with the theory of the construct.

\section{IMPLICATIONS AND LIMITATIONS}

The instrument presented here represents a major step forward in the development of a valid, reliable, and useful measure of EUC support. Such a measure is likely to be very useful to IS researchers wishing to study the impact of various contingency variables on the perceived support needed by end-users or on perceived support provided to them. Examples of such contingency variables include the computing experience of end-users, their learning styles, age (or maturity) of the information center, the nature of applications used, and organizational characteristics. This instrument should also prove useful in the study of the impact of EUC support on end-user satisfaction or on other dependent variables used to measure the overall effectiveness of EUC in an organization.

For IS practitioners, this instrument can serve as a basis for deciding on the mix of support services to be offered to end-users via an information center. The instrument 
Table 11: End-user computing sophistication and support needed: Comparison of means ( $t$-tests).

\begin{tabular}{lccc}
\hline Categories & $\begin{array}{c}\text { Sample Sizes } \\
\left(n_{1}, n_{2}\right)\end{array}$ & $t$ & $\begin{array}{c}p \\
\text { (one-tailed) }\end{array}$ \\
\hline $\begin{array}{l}\text { Non-programming end-users vs. } \\
\text { Command level users }\end{array}$ & $(42,37)$ & 1.66 & .05 \\
$\begin{array}{l}\text { Command level users vs. } \\
\text { End-user programmers }\end{array}$ & $(37,37)$ & .52 & .30 \\
$\begin{array}{l}\text { End-user programmers vs. } \\
\quad \text { Functional support personnel }\end{array}$ & $(37,47)$ & 1.34 & .09 \\
$\begin{array}{l}\text { Command level users vs. } \\
\text { Functional Support Personnel }\end{array}$ & $(37,47)$ & 1.66 & .05 \\
\hline
\end{tabular}

may also be used periodically to administer a survey that measures the progress attained by end-users and support staff in their respective roles over time. Such an exercise would help assess the long-term effectiveness of the information center.

Despite the rigorous methodology used in the development of this instrument, some cautions are in order. For instance, the ratio of items to data points in the factor analysis was 1:3.13, which is less than the recommended ratio of $1: 4$ or higher. Also, further testing is necessary to assess the instrument's test-retest reliability, and to better examine its convergent and discriminant validity using the multitrait-multimethod matrix method [11]. Further work is also necessary to test the instrument's validity and reliability in other nomological contexts in order to understand how the construct behaves in relationship with other constructs it is attempting to explain or predict (e.g., end-user satisfaction, EUC usage, IC effectiveness). This is a long-term process that will ultimately result in the strengthening of the nomological net around the construct of interest, that is, EUC support. This instrument is rather lengthy, so future research should also focus on developing a shorter version of this instrument while preserving its construct validity. [Received: May 17, 1993. Accepted: May 26, 1994.]

\section{REFERENCES}

[1] Alavi, M., Nelson, R.R., \& Weiss, I.R. Strategies for end-user computing: An integrative framework. Journal of MIS, 1987, 4(3), 29-49.

[2] Alavi, M., Nelson, R.R., \& Weiss, I.R. Managing end-user computing as a value-added resource. Journal of Information Systems Management, 1988, 5(3), 26-35.

[3] Amoroso, D.L., \& Cheney, P.H. Testing a causal model of end-user application effectiveness. Journal of MIS, 1991, 8(1), 63-89.

[4] Arkush, E., \& Stanton, S.A. Third-era information systems: Strategy development continued. Journal of Information Systems Management, 1987, 4(2), 66-69.

[5] Amoudse, D.M., \& Oullette, L.P. An introduction to the information center concept. Information Strategy, 1986, 3(2), 9-12.

[6] Bailey, J.E., \& Pearson, S.W. Development of a tool for measuring and analyzing computer user satisfaction. Management Science, 1983, 29(5), 530-545.

[7] Benson, D.H. A field study of end user computing: Findings and issues. MIS Quarterly, 1983, 7(4), $35-45$. 
[8] Bergeron, F. \& Berube, C. The management of the end-user environment: An empirical investigation. Information and Management, 1988, 14(2), $107-113$.

[9] Bergeron, F., Rivard, S., \& De Serre, L. Investigating the support role of the information center. MIS Quarterly, 1990, 14(3), 247-260.

[10] Brancheau, J.C., Vogel, D.R., \& Wetherbe, J.C. An investigation of the information center from the user's perspective. Data Base, 1985, 17(1), 4-17.

[11] Campbell, D.T., \& Fiske, D.W. Convergent and discriminant validation by the multitrait-multimethod matrix. Psychological Bulletin, 1959, 56, 81-105.

[12] Carr, H.H. Information centers: The IBM model vs. practice. MIS Quarterly, 1987, II(3), 325-338.

[13] Caudle, S.L., Gorr, W.L., Newcomer, K.E. Key information systems management issues for the public sector. MIS Quarterly, 1991, 15(2), 171-188.

[14] Christy, D.P. \& White, Jr., C.E. Structure and function of information centers: Case studies of six organizations. Information and Management, 1987, 13(2), 71-76.

[15] Doll, W.J., Torkzadeh, G. The measurement of end-user computing satisfaction. MIS Quarterly, 1988, 12(2), 259-274.

[16] Henderson, J.C., \& Treacy, M.E. Managing end-user computing for competitive advantage. Sloan Management Review, 1986, 27(2), 3-13.

[17] Huff, S.L., Munro, M.C., \& Martin, B.H. Growth stages of end user computing. Communications of the ACM, 1988, 31(5), 542-550.

[18] Igbaria, M., \& Nachman, S.A. Correlates of user satisfaction with end user computing: An exploratory study. Information and Management, 1990, 19(2), 73-82.

[19] Ives, B., Olson, M.H., \& Baroudi, J.J. The measurement of user information satisfaction. Communications of the $A C M, 1983,26(10), 785-793$.

[20] Jenkins, A.M., \& Ricketts, J.A. Development of an instrument to measure user satisfaction with management information systems. Report from the School of Business at Indiana University, Bloomington, IN: November, 1979.

[21] Kasper, O.M., \& Cerveny, R.P. A laboratory study of user characteristics and decision-making performance in end-user computing. Information and Management, 1985, 9(2), 87-96.

[22] Kerlinger, F.N. Foundations of behavioral research. New York: Holt, Rinehart, and Winston, 1973.

[23] Kim, J.-O., \& Mueller, C.W. Factor analysis statistical methods and practical issues. Sage University Paper series on Quantitative Applications in the Social Sciences, Series No. 07-014. Beverly Hills and London: Sage Publications, 1978.

[24] Kleinberg, E.R. Strategies for effective microcomputer management. Journal of Information Systems Management, 1986, 3(1), 27-35.

[25] Lederer, A.L., \& Spencer, V.L. The effective information center: Targeting the individual user for success. Journal of Systems Management, 1988, 39(1), 22-26.

[26] Leitheiser, R.L., \& Wetherbe, J.C. Approaches to end-user computing: Service may spell success. Journal of Information Systems Management, 1986, 3(1), 9-14.

[27] Leitheiser, R.L., \& Wetherte, J.C. Service support levels: An onganized approach to end-user compuling. MIS Quarterly, 1986, 10(4), 337-349.

[28] Loevinger, J. Objective tests as instruments of psychological theory. Psychological Reports, 1957, 3 , 635-694.

[29] Magal, S.R., \& Carr, H.H. An investigation of the effects of age, size, and hardware option on the critical success factors applicable to information centers. Journal of MIS, 1988, 4(4), 60-76.

[30] Necco, C.R., Gordon, C.L., \& Tsai, N.W. The information center approach for developing computerbased information systems. Information and Management, 1987, 13(2), 95-101.

[31] Nelson, R.R., \& Cheney, P.H. Training end-users: An exploratory study. MIS Quarterly, 1987, II(4), 547-559.

[32] Nunnally, J.C. Psychometric theory. New York: McGraw-Hill, 1978.

[33] O'Donnell, D.J., \& March, S.T. End-user computing environments-Finding a balance between productivity and control. Information and Management, 1987, 13(2), 77-84.

[34] Panko, R.R. Directions and issues in end user computing. Information Systems and Operations Research, 1987, 25(3), 181-197.

[35] PC Week. News Digest. 1992 (November), 151.

[36] Porter, L.R., \& Gogan, J.L. Coming to terms with end-user systems integration. Journal of Information Systems Management, 1988, 5(1), 8-16. 
[37] Raymond, L. Organizational characteristics and MIS success in the context of small business. MIS Quarterly, 1985, 9(1), 37-52.

[38] Rivard, S. Successful implementation of end-user computing. Interfaces, 1987, 17(3), 25-33.

[39] Rivard, S., \& Huff, S.L. User developed applications: Evaluations of success from the DP department perspective. MIS Quarterly, 1984, 8(1), 39-49.

[40] Rockart, J.F., \& Flannery, L.S. The management of end user computing. Communications of the $A C M, 1983,26(10), 776-784$

[41] Steele, J., \& Bottomley, D. Channeling the end-user computing initiative: A case study. Journal of Information Systems Management, 1988, 5(2), 49-55.

[42] Stevens, J. Applied multivariate statistics for the social sciences. Hillsdale, NJ: Laurence Eribaum Associates, 1986.

[43] White, C.E., Jr., \& Christy, D.P. The information center concept: A normative model and a study of six installations. MIS Quarterly, 1987, 7(4), 451-458.

Rajesh Mirani is Assistant Professor in the Information and Quantitative Sciences Department, Merrick School of Business, University of Baltimore. His research interests focus on the management of end-user computing and the justification of proposed information systems projects. His papers have been published in MIS Quarterly, Joumal of Management Information Systems, Journal of Systems Management, and Journal of End User Computing. He is also a frequent contributor to professional conferences.

William R. King is University Professor in the Katz Graduate School of Business at the University of Pittsburgh. He is the author of more than a dozen books and 200 papers that have appeared in the leading joumals in management science and information systems. He has served as president of The Institute of Management Sciences (TIMS), as senior editor of the MIS Quarterly, and as general chair of the Intemational Conference on Information Systems (ICIS). 